\title{
Training Health Workers to Prevent and Manage Post-Partum Haemorrhage (PPH)
}

Nina Cooper MBBS BSc AICSMํ, Stephen O’Brien BMBS PhD², Dimitrios Siassakos MD $\mathrm{MRCOG}^{1}$

1. Elizabeth Garrett Anderson Wing, University College Hospital, 25 Grafton Way, London, WC1E 6DB, UK

2. Women \& Children's Department, Gloucestershire Royal Hospital, Great Western Road, Gloucester, GL1 3NN UK

Corresponding Author: Dr Dimitrios Siassakos

Words $5433+2$ pages of figures $=$ approx. 6433 words 


\section{Abstract}

Postpartum haemorrhage $(\mathrm{PPH})$ is the second greatest direct cause of maternal death in the United Kingdom and rates of PPH continue to rise despite advances in clinical care. Training workers to manage postpartum haemorrhage involves improvement of technical and nontechnical skills in the context of a multidisciplinary team (MDT). Management of PPH should begin in the antenatal period, with identification of high-risk women and referral for multispecialty input. Training for the acute management of PPH should involve all members of the labour ward team and beyond, including haematology and non-clinical staff. Simulation-based training, didactic teaching and hybrid obstetric emergency courses are current options for training workers. Non-technical skills should also be taught, including specific training on communication, leadership, situational awareness and team-working skills. Improving management of obstetric emergencies requires thorough antenatal and intrapartum risk assessment, optimising knowledge and non-technical skills of individual members of the team, improving collaboration of the MDT, better simulation training and adjusting local infrastructure.

\section{Keywords}

Postpartum haemorrhage, obstetric anaesthesia, obstetric emergencies, multiprofessional training, simulation training, CRM training 


\section{Introduction}

Postpartum haemorrhage (PPH) accounts for $25 \%$ of maternal deaths globally and is the second greatest cause of direct maternal death in the UK (1, 2). The 2018 UK and Ireland Confidential Enquiries into Maternal Deaths report published by MBRRACE-UK (Mothers and Babies Reducing Risk through Audits and Confidential Enquiries across the UK) revealed a 99\% increase in haemorrhage since the previous 2013-15 report, and rates are known to be increasing in high resource settings in general $(2,3)$.

The National Maternity Review 'Better Births' document advocates that 'those who work together should train together' (4), and a multidisciplinary team (MDT) approach is recommended for women presenting with risk factors for PPH by both the Royal College of Obstetricians and Gynaecologists (RCOG) and Royal College of Anaesthetists (RCoA) (5, 30). The 2018 MBRRACE-UK report demonstrated that women with morbidly adherent placenta had large variations in their diagnosis and care (2), particularly with regards to antenatal MDT input. It is fundamental that women at high risk of PPH are identified early to allow an MDT approach to planning a tailored labour and delivery.

Failure of communication and teamwork has been identified as one of the most frequent causes of perinatal death or permanent disability $(2,6)$. Better MDT training in the management of obstetric emergencies has been recommended by the Institute for Healthcare Improvement (IHI) (7). Delays in identification of PPH and slow escalation to senior members of staff have been recognised as contributors to maternal death (2).

Improving teamwork has been demonstrated to make maternity teams more effective and safe (8). Multidisciplinary joint simulation training has been developed based on aviation models of crew resource management (CRM) (9) and emphasises the importance of communication, leadership, resource management and situational awareness in the context of an obstetric emergency (10). There is growing evidence that MDT emergency obstetric drills training can improve clinical and organisational outcomes $(6,11-15)$, however more 
research is required to identify the vital training components which translate into improved patient safety in the long-term (16). The UK PROMPT (PRactical Obstetric MultiProfessional Training) model of evidence-based multidisciplinary training is recognised to improve neonatal outcomes and has reduced local litigation claims by $91 \%(15,17)$. In addition to the aforementioned clinical and organisational benefits, better training for managing obstetric emergencies improves patient and relative satisfaction (6). Despite these advances, rates of PPH continue to increase (2). We aim to explore the current strategies for training workers to prevent and manage $\mathrm{PPH}$.

\section{Technical Skills: Improving Clinical Knowledge}

It is estimated that there are 10 'near misses' for every maternal death which occurs from $\mathrm{PPH}$ (18). Improving clinical skills as well as knowledge of the risk factors of PPH are instrumental in preventing maternal morbidity and mortality. A multidisciplinary approach, including antenatal anaesthetist input, is currently recommended by the RCOG in women with suspected placenta praevia or accreta (5), however risk factors for PPH extend beyond this pathology. Other predisposing factors are listed in table $1(18,19)$. It is vital that maternity units identify at-risk women to allow for early MDT input.

Prevention is better than cure. Evidence-based approaches to reducing the incidence and adverse maternal outcomes associated with postpartum haemorrhage include administration of tranexamic acid (20), prompt blood transfusion (21) and active management of the third stage of labour $(18,22)$. A recent Cochrane review of 140 randomised trials, including almost 89000 women, found that combinations of uterotonics (ergometrine plus oxytocin; misoprostol plus oxytocin) and carbocetin were better at preventing $\mathrm{PPH} \geq 500 \mathrm{ml}$ than oxytocin alone. In cases of $\mathrm{PPH} \geq 1000 \mathrm{ml}$, an ergometrine plus oxytocin combination was more effective than oxytocin alone, with data suggestive that carbocetin and misoprostol plus oxytocin were also superior. Importantly, it is noted that combination regimes were noted to have significantly more side effects (23). Ongoing trials include the COPE study, 
exploring intravenous (IV) oxytocin versus intramuscular (IM) haemabate as first-line management of PPH (24), and the IMox study, comparing the use of intramuscular carbetocin, syntocinon and syntometrine for the third stage of labour following vaginal birth (25). These studies will shed important light on the best evidence-based approach for managing $\mathrm{PPH}$.

Early identification of PPH allows for prompt commencement of management. Training workers to improve their knowledge of PPH can be achieved via didactic teaching or simulation training. Standardised courses include PROMPT, MOET (Managing Obstetric Emergencies and Trauma) and ALSO (Advanced Life Support in Obstetrics) $(15,17,26,27)$ .These are multi-professional courses which vary in structure and, in varying degrees, consist of lectures, small-group teaching, simulation and training on models (28). Evidencebased memory aids can be taught in order to facilitate recall of fundamental treatment steps in $\mathrm{PPH}$ and have beenshown to reduce the chances of peripartum hysterectomy $(18,29)$. Simpler algorithms that are easier to recall are preferable, and basic prompts should to convey the overarching themes of treatment. In the case of PPH, the anaesthetist must complete an A-E approach, resuscitate and administer tranexamic acid; the obstetricians and midwives must stop the bleeding. The importance of communication amongst members of the MDT should also be emphasised.

Massive obstetric haemorrhage is the most common reason a woman is admitted to the intensive care unit (ICU) postpartum $(30,31)$. Skilled obstetric anaesthetists are fundamental in improving patient outcomes and paper-based $\mathrm{PPH}$ protocols may be useful for anaesthetists to use in a labour ward setting (32). Simple interventions that any member of the multidisciplinary team can perform include active patient warming, prompt sending of pathology specimens and running point of care tests.

Current UK national guidance provides normal values above which coagulation parameters should be kept during a PPH. Point of care coagulation (viscoelastic) testing would allow 
'real-time' monitoring of these values, offering obstetricians and anaesthetists a method of identifying if major haemorrhage is secondary to a coagulopathy or if it is purely obstetric in nature (33). This could become a vital step in management of major PPH, particularly as it will impact the nature of blood product replacement.

Indeed, improving the obstetrician-anaesthetist relationship is an evidence-based strategy for improving patient safety $(32,34)$. The RCoA, RCOG and Royal College of Midwives 2018 'care of the critically ill woman in childbirth' document recommends cross-specialty experience to help develop their skills, such as midwives having short attachments in a critical care unit (30). Training programmes must remain up-to-date with the latest evidence from all specialties involved in managing $\mathrm{PPH}$, and update their recommendations accordingly.

\section{Obstetric Emergency Simulation Training}

Key players in the management of PPH include clinical staff such as obstetricians, midwives, anaesthetists and haematologists, as well as auxiliary staff such as porters and blood bank personnel. The RCoA advocates multidisplinary team training using simulation-based techniques (30). Training should ideally include all stakeholders involved in the emergency obstetric response; however this can be practically challenging due to the pressures of clinical provision, limited availability of staff and the financial cost of training. Many papers examining obstetric emergency simulation training are based on joint midwife-obstetrician programmes $(16,35,36)$. An oft overlooked member of the team is the woman herself $(35)$.

Woman-centred outcomes should be prioritised when designing a training programme for PPH. An International Delphi consensus study have published nine standardised core outcomes for preventing PPH and twelve core outcomes for treatment (Figure 1)(37). All future training programmes, and proposed interventions, should be evaluated in relation to these patient-centred outcomes and to allow standardised assessment of proposed interventions. 
The SaFE Study (Safety and Fire Drill Evaluation study) was a 2x2 factorial randomised controlled trial that looked at simulation centre and in-hospital obstetric emergencies training (including a PPH scenario) with and without an additional CRM teamwork course (35). They found that participants training in teams are less likely to miss steps in management, and it was apparent that it is not a lack of knowledge, but adequate training, that leads to errors in management $(11,35)$. Interestingly, safety scores were significantly higher in teams trained locally versus at a simulation centre. Other benefits of in-house training include the ability to identify gaps in their service and necessary infrastructural change, for instance developing protocols, improving accessibility of guidelines or installation of haemorrhage boxes $(5,6$, $11,12)$.

Optimising maternal delivery experience and perception of care is vital, particularly as worse maternal satisfaction is associated with an increased risk of litigation (38). In the SaFE study there was no significant difference in womens' perception of care between individuals who had attended a team-based CRM course (in addition to simulation training) compared with those who had not (35). CRM training principles are based on a cockpit environment, and when translating to a medical setting, PPH scenarios are analogous to aircraft passengers being present in the cockpit at the time of an emergency. The lack of improvement in womens' perception of care may stem from the fact that CRM advocates good communication between members of the team ('the pilots') and does not specifically identify the woman as part of the communication model $(35,39-42)$. Therefore, it is imperative to consider the woman as a central stakeholder when developing training models for $\mathrm{PPH}$.

Local 'in-house' training using patient-actors, high-fidelity mannequins and low cost props has been shown to be a clinically effective method of providing multi-professional training (6, 11). There are currently no studies comparing of low- versus high fidelity models for management of PPH (16). In a study comparing high- versus low-fidelity models in shoulder dystocia simulation, participants trained with the high fidelity model had a significantly higher rate of successful delivery and a shorter head-to-body delivery time (43). There was no 
improvement in communication skills depending on training model and those taught on the high fidelity model were less likely to call for paediatric support. This highlights that the wider management of emergencies and patient communication skills need to be incorporated into obstetric emergencies skills training in general (6).

Mandatory attendance at a one-day obstetrics emergency training course, including training on $\mathrm{PPH}$, was implemented at a tertiary maternity unit in a teaching hospital over a 5 year period, producing a sustained significant reduction in low 5-minute Apgar scores and hypoxic ischaemic encephalopathy (15). Potential aversion to mandatory simulation training has been proposed due to individuals' intimidation of role-play, however the most frequent cause of non-attendance is lack of time due to clinical commitments $(44,45)$. The clinical effectiveness of training must be cross-referenced with the financial costs associated with implementing multiprofessional training programmes. At one institution, the cost of implementing 'PROMPT' training was €23 000 per 1000 births in year one and €22 000 per financial year thereafter. This equated to staff accounting for $90 \%$ of total expenditure (46). Given regular, integrated MDT acute obstetric training is shown to improve knowledge, practical skills and team performance, and has the potential to prevent future errors (15-17), it may represent a valuable future training strategy once greater cost-benefit analysis is undertaken.

\section{Non-Technical Skills: Communication, Teamwork and Leadership}

\section{Communication}

Communication failures are a leading avoidable cause of adverse events in obstetric emergencies (47). Analysis of communication has been performed within the aviation industry and, less extensively, in obstetrics (48). Communication can be broken down into commands, enquiries, responses, observations, interruptions and intentions (49). In the obstetric setting, multidisciplinary teams that have been trained in specific teamwork behaviours, such as CRM, use more directed commands compared with those who have 
not, resulting in tasks being more likely to be acknowledged and performed (48). A systematic review of MDT training in obstetric emergencies identified improved communication in three studies (including two randomised-controlled trials) $(6,43,50)$. Suboptimal communication and undirected commands are more likely to result in errors, and therefore there is potential that better non-technical training (i.e. non-clinical focussed simulation) could translate into improved safety (48). It would be beneficial to improve communication between staff immediately present at the time of $\mathrm{PPH}$, as well as those recruited to aid management such as anaesthetists and haematologists. More work is required to ascertain the optimum combination of clinical and non-clinical elements of a training programme which are required to improve long-term outcomes.

\section{Teamwork}

Teamwork is defined as a combined effort by a group to achieve a common goal (51). Interestingly, perception of teamwork may differ based on job role, with one survey reporting that fewer midwives and anaesthetists describe good teamwork in their units compared to obstetricians (37-39\% vs. 52-62\%) (52). In a study of the simulated management of eclampsia, using administration of magnesium sulfate as a surrogate endpoint for clinical efficacy, the researchers found that teams with higher 'teamwork' scores were more efficient and had better clinical conduct (53). Similarly, a statistically significant improvement in team performance was identified by a Dutch study of 24 maternity units after simulation training of amniotic fluid embolism and shoulder dystocia (54). It would be useful to generate a surrogate endpoint for PPH management, for instance time to manual uterine compression or administration of oxytocin, in order to quantitatively verify the aspects of team working that are vital for improving performance.

Key features of effective teams include sufficient knowledge and technical skills to manage the emergency, as well as situational awareness, strong leadership and structure communication. Confusion about one's role and responsibilities within a team, coupled with 
poor communication, have been identified as contributors to adverse outcomes in the management of obstetric emergencies (51). Key methods of tackling these issues this include high quality handovers, a clear statement of each team member's role and training, a summary of the current clinical situation and a leader who verbalises this information for all members of the team, and the mother, to hear $(51,55)$. There is now a drive to move away from individual blame and, instead, to improve team working in obstetrics (11).

\section{Leadership}

Lack of leadership has been identified as an issue when managing an obstetric emergency such as PPH. A survey of over 600 healthcare professionals in the USA revealed that up to two-thirds of those questioned felt that there was a lack of leadership in obstetrics (56). The leader can vary depending on the situation encountered and the other members of the team present. Factors that should be considered include technical experience, knowledge of the local environment and an understanding of the members of the team and their expertise (51).

Seniority does not always equate to the best leader; the individual with most experience has been demonstrated to be the most appropriate person leading an emergency (44). A good leader should flatten out hierarchy so that all members of the team feel able to contribute (56). A key step in establishing leadership is verbalising this role, for instance saying 'I am the leader' or 'I will lead now'. The leader should stand back from the situation so they have an overview of all members and actions of the team and to enable them to direct members in a closed-loop communication style.

Mesinioti et al explore the enactment of leadership in obstetric emergencies and in the presence of a conscious patient as part of the scenario (57). They describe leadership as the actions of the material body as well as verbal and nonverbal communication. Spatial zones have been identified as clearly correlated with an assertion of leadership, that is the leader (often the most senior doctor) stands at the bedside and in the centre of the scenario. 
Furthermore, upon analysis of the typology of questions given by the leader (senior doctor), there was a clear trend in phrases used for diagnosing/assessing the situation, allocating tasks, setting an agenda, seeking confirmation and requesting information. Teams which performed better had superior interactions between individual members of the team. PPH training could involve instruction of physical spaces that should be occupied by those in control.

\section{Summary}

There is a complex interplay of factors which determine the successful management of postpartum haemorrhage and this is summarised in figure 2. The management of postpartum haemorrhage begins in the antenatal period. A multidisciplinary team should be involved early when risk factors for PPH are identified. Close monitoring during labour and delivery, with modification of risk factors where possible, is vital. If $\mathrm{PPH}$ is identified, team working is critical for ensuring successful management. Currently, multi-professional simulation training is advocated by both the RCOG and RCoA (30). Improving technical and non-technical skills are both strategies for better managing obstetric emergencies.

\section{PRACTICE POINTS}

- Rates of PPH continue to rise due to more high-risk pregnancies occurring. Early recognition and multidisciplinary assessment of women who are at risk is the first step in managing women who may experience $\mathrm{PPH}$

- Training in PPH should focus on both technical and non-technical skills; currently multi-professional simulation-based training is recommended

- Ideally simulation training should involve all stakeholders, including non-clinical personnel

- In-house training allows for identification of infrastructure issues and development of local management pathways 
- Training programmes must adopt an evidence-based approach in teaching the best management of $\mathrm{PPH}$; this requires multi-specialty input

\section{RESEARCH AGENDA}

- Criteria for high risk women may need to be developed to facilitate early referral to other members of the MDT

- Vital components for a training programme need to be established, particularly those which translate into improved clinical outcomes

- Point-of-care testing should be evaluated for 'real-time' monitoring coagulopathy in major obstetric haemorrhage. If successful, both obstetricians and anaesthetists will require training in the application of this

- Optimum uterotonics are under investigation and this may impact existing PPH algorithms

\section{MCQs}

\section{Question 1}

When it comes to simulation-based training, identify which of the following statements are true or false:

1. Closed-loop communication is better than using undirected commands

2. A clear hierarchy is better for establishing authority and allows a leader to be in control

3. The most senior member should be the leader

4. 'In-house' simulation is preferable to training in a specialist simulation centre

5. The presence of a patient-actor is beneficial in simulation training

Answers: 1. True, 2. False, 3: False, 4. True, 5: True

Explanation 
1. True. Closed-loop communication means using more directed commands, resulting in tasks being more likely to be acknowledged and performed. Suboptimal communication and undirected commands are more likely to result in errors.

2. False. A good leader should flatten out hierarchy so that all members of the team feel able to contribute

3. False. The best leader is usually the person with the most experience in dealing with that scenario, and may not always be the most senior person in the team.

4. True. Patient safety scores are significantly higher in teams trained locally versus at a simulation centre

5. True. Local 'in-house' training using patient-actors has been shown to be a clinically effective method of providing multi-professional training

\section{Question 2}

When training for managing PPH, which of the following statements are true:

1. PPH training should be didactic for junior members of the team

2. PPH training should only involve midwives and obstetricians

3. PPH training should focus on the acute actions needed in an emergency scenario

4. Improving maternal satisfaction is an important factor when designing a training programme

5. Anaesthetists require specialist $\mathrm{PPH}$ training separate to other specialties

Answers: 1. False, 2. False, 3: False, 4. True, 5. False

Explanation

1. False. Simulation training is beneficial at all levels in the multidisciplinary team and should involve members with different skillsets and knowledge 
2. False. PPH training should ideally involve clinical and nonclinical staff, including obstetricians, midwives, anaesthetists and haematologists

3. False. PPH training should aim to advise on risk factors and modifiable factors that can be identified in the antenatal period, as well as the acute actions that can be undertaken in the event of an emergency

4. True. Improving maternal satisfaction is important as it reduces chances of litigation and improves the woman's experience of labour.

5. False. The RCoA recommends multidisciplinary training with members of the maternity team who may be involved in managing $\mathrm{PPH}$

\section{ACKNOWLEDGEMENTS}

None

CONFLICT OF INTERESTS

None

FIGURE LEGENDS

Table 1: Risk factors for PPH (Adapted from RCOG PPH Guidance (19))

Figure 1: Patient-centred outcomes for prevention and management of PPH (37)

Figure 2: A schematic of the patient-centred approach to design a training programme for the management of PPH 


\begin{tabular}{|ll|}
\hline RISK FACTOR & OR (95\% CI) \\
\hline TONE & $3.30(1.00-10.60)(58)$ \\
\hline Multiple pregnancy & $4.70(2.40-9.10)(59)$ \\
Previous PPH & $3.60(1.20-10.20)(58)$ \\
Fetal macrosomia & $2.11(1.62-2.76)(60)$ \\
Failure to progress in second stage & $2.40(1.90-2.90)(59)$ \\
& $3.40(2.40-4.70)(61)$ \\
Prolonged third stage & $1.90(1.20-2.90)(62)$ \\
General anaesthesia & $7.60(4.20-13.50)(58)$ \\
& $2.90(1.90-4.50)(62)$ \\
\hline THROMBIN & \\
\hline Pre-eclampsia & \\
& $5.00(3.00-8.50)(58)$ \\
\hline TRAUMA & $2.20(1.30-3.70)(62)$ \\
\hline Episiotomy & \\
\hline Placenta accreta & $4.70(2.60-8.40)(58)$ \\
& $2.18(1.68-2.76)(60)$ \\
& $1.70(1.20-2.50)(59)$ \\
\hline TISSUE & $1.40(1.04-1.87)(60)$ \\
\hline Retained placenta & $2.40(2.00-2.80)(61)$ \\
& $1.70(1.10-2.50)(59)$ \\
\hline & \\
\hline
\end{tabular}




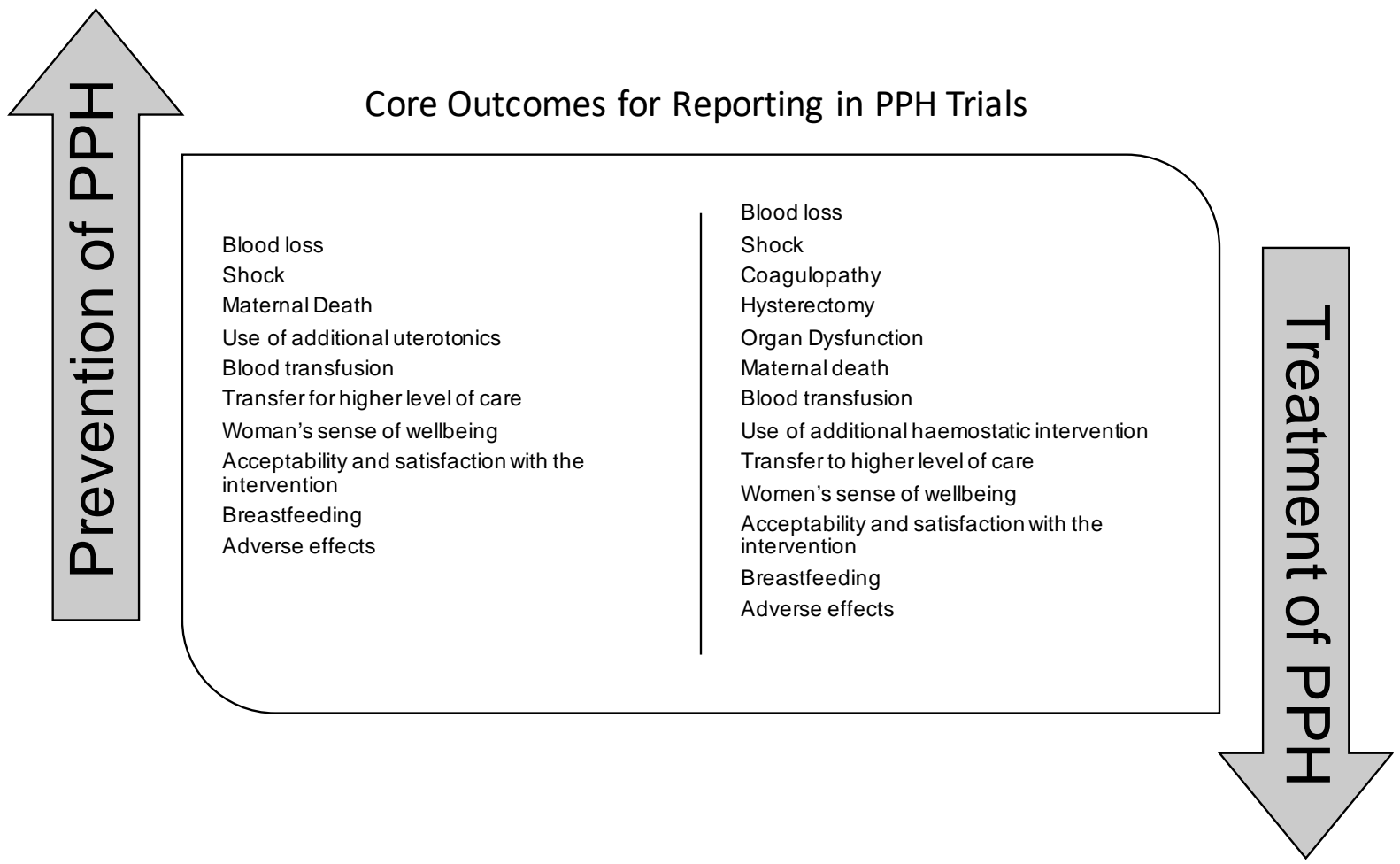




\section{ANTENATAL ASSESSMENT}

Identification of Risk Factors

Modification of Risk Factors

Antenatal MDT Assessment

Counselling of birthing options

\section{INTRAPARTUM ASSESSMENT}

Identification of Risk Factors

Modification of Risk Factors

Early recognition of $\mathrm{PPH}$

High level of care in labour

\section{INDIVIDUAL MEDICAL PROFESSIONALS}

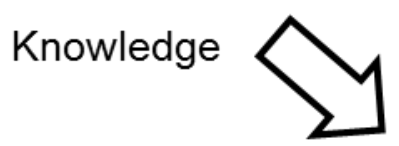

Expertise

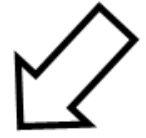

Experience

Situational Awareness

Communication Skills

Understanding of Team Members

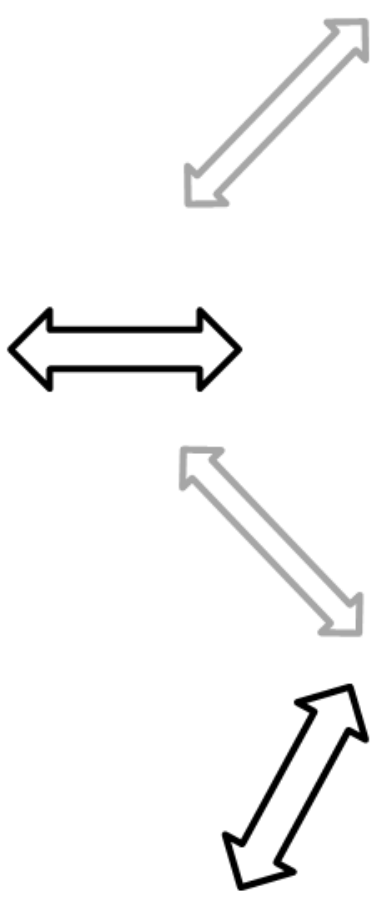

SIMULATION TRAINING

Technical skills

Non-technical skills

Improved communication

Improved team-working

Knowledge of Local Protocols

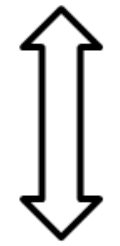

\section{THE PATIENT}

Maternal Safety

Maternal Satisfaction

Partner/Family Support

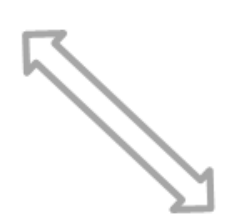

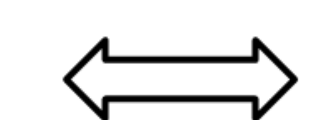

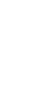

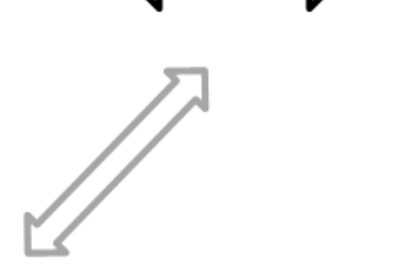

MULTIDISCIPLINARY TEAM

Allocation of a Leader Delegation of Tasks Appropriate Team Members Closed-Loop Communication Flattening of Hierarchy 


\section{REFERENCES}

1. Say L, Chou D, Gemmill A, Tunçalp Ö, Moller AB, Daniels J, Gülmezoglu AM, Temmerman M, Alkema L. Global causes of maternal death: a WHO systematic analysis. Lancet Glob Health. 2014;2(6):e323-33. doi: 10.1016/S2214109X(14)70227-X.

2. Knight M, Bunch K, Tuffnell D, Jayakody H, Shakespeare J, Kotnis R et al. Saving Lives, Improving Mothers' Care [Internet]. MMBRACE-UK; 2018. Available from: https://www.npeu.ox.ac.uk/downloads/files/mbrrace-uk/reports/MBRRACEUK\%20Maternal\%20Report\%202018\%20-\%20Web\%20Version.pdf

3. Knight M, Tuffnell D, Kenyon S, Shakespeare J, Gray R, Kurinczuk JJ (Eds.) On behalf of MBRRACE-UK. Saving lives, improving mothers' care-surveillance of maternal deaths in the UK 2011-13 and lessons learned to inform maternity care from the UK and Ireland Confidential Enquiries into Maternal Deaths and Morbidity 2009-13. Oxford: National Perinatal Epidemiology Unit, University of Oxford; 2015

4. National Maternity Review. Better births: Improving outcomes of maternity services in England. A Five Year Forward View for maternity care. 2016.

5. Jauniaux ERM, Alfirevic Z, Bhide AG, Belfort MA, Burton GJ, Collins SL, Dornan S, Jurkovic D, Kayem G, Kingdom J, Silver R, Sentilhes $L$ on behalf of the Royal College of Obstetricians and Gynaecologists. Placenta Praevia and Placenta Accreta: Diagnosis and Management. Green-top Guideline No. 27a. BJOG 2018

6. Crofts JF, Bartlett C, Ellis D, Winter C, Donald F, Hunt LP, Draycott TJ. Patient-actor perception of care: a comparison of obstetric emergency training using manikins and patient-actors. BMJ Quality \& Safety. 2008 Feb 1;17(1):20-4.

7. How-to Guide: Prevent Obstetrical Adverse Events. Cambridge, MA: Institute for Healthcare Improvement; 2012. (Available at www.ihi.org).

8. Siassakos D, Fox R, Bristowe K, Angouri J, Hambly H, Robson L, Draycott TJ. What makes maternity teams effective and safe? Lessons from a series of research on 
teamwork, leadership and team training. Acta obstetricia et gynecologica Scandinavica. 2013 Nov 1;92(11):1239-43.

9. Orasanu, J., 1990. Shared mental models and crew decision making.

10. Guise JM, Segel S. Teamwork in obstetric critical care. Best Practice \& Research Clinical Obstetrics \& Gynaecology. 2008 Oct 1;22(5):937-51.

11. *Siassakos D, Crofts JF, Winter C, Weiner CP, Draycott TJ. The active components of effective training in obstetric emergencies. BJOG: An International Journal of Obstetrics \& Gynaecology. 2009 Jul 1;116(8):1028-32.

12. Draycott TJ, Crofts JF, Ash JP, Wilson LV, Yard E, Sibanda T, Whitelaw A. Improving neonatal outcome through practical shoulder dystocia training. Obstetrics \& Gynecology. 2008 Jul 1;112(1):14-20.

13. Pratt SD, Mann S, Salisbury M, Greenberg P, Marcus R, Stabile B, McNamee P, Nielsen P, Sachs BP. Impact of CRM-based team training on obstetric outcomes and clinicians' patient safety attitudes. Joint Commission journal on quality and patient safety. 2007 Dec 1;33(12):720-5.

14. Scholefield $\mathrm{H}$. Embedding quality improvement and patient safety at Liverpool Women's NHS Foundation Trust. Best practice \& research clinical obstetrics \& gynaecology. 2007 Aug 1;21(4):593-607.

15. *Draycott T, Sibanda T, Owen L, Akande V, Winter C, Reading S, Whitelaw A. Does training in obstetric emergencies improve neonatal outcome?. BJOG: An International Journal of Obstetrics \& Gynaecology. 2006 Feb;113(2):177-82.

16. Merién AE, van de Ven J, Mol BW, Houterman S, Oei SG. Multidisciplinary team training in a simulation setting for acute obstetric emergencies: a systematic review. Obstetric Anesthesia Digest. 2011 Jun 1;31(2):83-4.

17. *Impact - PROMPT Maternity [Internet]. PROMPT Maternity. 2019 [cited 18 February 2019]. Available from: http://www.promptmaternity.org/impact/

18. Chandraharan E, Krishna A. Diagnosis and management of postpartum haemorrhage. BMJ. 2017 Sep 27;358:j3875. 
19. Mavrides E, Allard S, Chandraharan E, Collins P, Green L, Hunt BJ, Riris S, Thomson AJ on behalf of the Royal College of Obstetricians and Gyna ecologists. Prevention and management of postpartum haemorrhage.BJOG 2016;124:e106e149.

20. Shakur H, Roberts I, Fawole B, Chaudhri R, El-Sheikh M, Akintan A, Qureshi Z, Kidanto H, Vwalika B, Abdulkadir A, Etuk S. Effect of early tranexamic acid administration on mortality, hysterectomy, and other morbidities in women with postpartum haemorrhage (WOMAN): an international, randomised, double-blind, placebo-controlled trial. The Lancet. 2017 May 27;389(10084):2105-16.

21. Holcomb JB, Tilley BC, Baraniuk S, Fox EE, Wade CE, Podbielski JM, Del Junco DJ, Brasel KJ, Bulger EM, Callcut RA, Cohen MJ. Transfusion of plasma, platelets, and red blood cells in a $1: 1: 1$ vs a $1: 1: 2$ ratio and mortality in patients with severe trauma: the PROPPR randomized clinical trial. Jama. 2015 Feb 3;313(5):471-82.

22. Prendiville WJ, Harding JE, Elbourne DR, Stirrat GM. The Bristol third stage trial: active versus physiological management of third stage of labour. Bmj. 1988 Nov 19;297(6659):1295-300.

23. Gallos ID, Papadopoulou A, Man R, Athanasopoulos N, Tobias A, Price MJ, Williams MJ, Diaz V, Pasquale J, Chamillard M, Widmer M. Uterotonic agents for preventing postpartum haemorrhage: a network meta-analysis. Cochrane Database of Systematic Reviews. 2018(12).

24. Team C. COPE Study [Internet]. Copestudy.uk. 2019 [cited 18 February 2019]. Available from: http://copestudy.uk/

25. IMox study [Internet]. Health Research Authority. 2019 [cited 18 February 2019]. Available from: https://www.hra.nhs.uk/planning-and-improving-research/applicationsummaries/research-summaries/imox-study/

26. Managing Medical and Obstetric Emergencies and Trauma [Internet]. Alsg.org. 2019 [cited 18 February 2019]. Available from: https://www.alsg.org/en/files/KFactsheet.pdf 
27. Advanced Life Support in Obstetrics (ALSO®) [Internet]. Aafp.org. 2019 [cited 18 February 2019]. Available from: https://www.aafp.org/cme/programs/also.html

28. Black RS, Brocklehurst P. A systematic review of training in acute obstetric emergencies. BJOG: An International Journal of Obstetrics \& Gynaecology. 2003 Sep;110(9):837-41.

29. Varatharajan L, Chandraharan E, Sutton J, Lowe V, Arulkumaran S. Outcome of the management of massive postpartum hemorrhage using the algorithm "HEMOSTASIS". International Journal of Gynecology \& Obstetrics. 2011 May;113(2):152-4.

30. Care of the critically ill woman in childbirth; enhanced maternal care [Internet]. Royal College of Anaesthetists; 2018 [cited 18 February 2019]. Available from: https://www.rcoa.ac.uk/system/files/EMC-Guidelines2018.pdf

31. Female admissions (aged 16-50 years) to adult, general critical care units in England, Wales and Northern Ireland. ICNARC CMP Obstetrics. ICNARC, 2009 Available from: https://www.icnarc.org/Our-Audit/Audits/Cmp/Our-National$\underline{\text { Analyses/Obstetrics }}$

32. Ring L, Landau R. Postpartum Hemorrhage: Anesthesia Management. In fSeminars in perinatology 2018 Nov 14 . WB Saunders.

33. Collis R, Guasch E. Managing major obstetric haemorrhage: Pharmacotherapy and transfusion. Best practice \& Research Clinical Anaesthesiology. 2017 Mar $1 ; 31(1): 107-24$.

34. Cooper JB. Critical Role of the Surgeon-Anesthesiologist Relationship for Patient Safety. Anesthesiology: The Journal of the American Society of Anesthesiologists. 2018 Sep 1;129(3):402-5.

35. *Crofts JF, Ellis D, Draycott TJ, Winter C, Hunt LP, Akande VA. Change in knowledge of midwives and obstetricians following obstetric emergency training: a randomised controlled trial of local hospital, simulation centre and teamwork training. 
BJOG: An International Journal of Obstetrics \& Gynaecology. 2007 Dec 1;114(12):1534-41.

36. Nielsen PE, Goldman MB, Mann S, Shapiro DE, Marcus RG, Pratt SD, Greenberg P, McNamee P, Salisbury M, Birnbach DJ, Gluck PA. Effects of teamwork training on adverse outcomes and process of care in labor and delivery: a randomized controlled trial. Obstetrics \& Gynecology. 2007 Jan 1;109(1):48-55.

37. Meher S, Cuthbert A, Kirkham JJ, Williamson P, Abalos E, Aflaifel N, Bhutta ZA, Bishop A, Blum J, Collins P, Devane D. Core outcome sets for prevention and treatment of postpartum haemorrhage: an international Delphi consensus study. BJOG: An International Journal of Obstetrics \& Gynaecology. 2019 Jan;126(1):83-93.

38. Hickson GB, Clayton EW, Githens PB, Sloan FA. Factors that prompted families to file medical malpractice claims following perinatal injuries. Jama. 1992 Mar $11 ; 267(10): 1359-63$.

39. Salas E, Burke CS, Cannon-Bowers JA. What we know about designing and delivering team training: tips and guidelines. Creating, implementing, and managing effective training and development: State-of-the-art lessons for practice. 2002:23459.

40. Siassakos D, Draycott TJ, Crofts JF, Hunt LP, Winter C, Fox R. More to teamwork than knowledge, skill and attitude. BJOG: An International Journal of Obstetrics \& Gynaecology. 2010 Sep;117(10):1262-9.

41. *Siassakos D, Fox R, Crofts JF, Hunt LP, Winter C, Draycott TJ. The management of a simulated emergency: better teamwork, better performance. Resuscitation. 2011 Feb 1;82(2):203-6.

42. *Siassakos D, Crofts J, Winter C, Draycott T. Multiprofessional 'fire-drill' training in the labour ward. The Obstetrician \& Gynaecologist 2009;11:55-60

43. *Crofts JF, Bartlett C, Ellis D, Hunt LP, Fox R, Draycott TJ. Training for shoulder dystocia: a trial of simulation using low-fidelity and high-fidelity mannequins.

Obstetrics \& Gynecology. 2006 Dec 1;108(6):1477-85. 
44. Bristowe K, Siassakos D, Hambly H, Angouri J, Yelland A, Draycott TJ, Fox R. Teamwork for clinical emergencies: interprofessional focus group analysis and triangulation with simulation. Qualitative health research. 2012 Oct;22(10):1383-94.

45. Wilson E, Janssens S, Hewett DG, Jolly B, Beckmann M. Simulation training in obstetrics and gynaecology: What's happening on the frontline?. Australian and New Zealand Journal of Obstetrics and Gynaecology. 2016 Oct 1;56(5):496-502.

46. Yau CWH, Pizzo E, Morris S, Odd DE, Winter C, Draycott TJ. The cost of local, multiprofessional obstetric emergencies training. Acta Obst Gyne Scand. 2016 Oct;95(10):1111-9.

47. Wilson RM, Runciman WB, Gibberd RW, Harrison BT, Newby L, Hamilton JD. The quality in Australian health care study. Medical journal of Australia. 1995 Nov;163(9):458-71.

48. Siassakos D, Draycott T, Montague I, Harris M. Content analysis of team communication in an obstetric emergency scenario. Journal of Obstetrics and Gynaecology. 2009 Jan 1;29(6):499-503.

49. Kanki BG, Foushee HC. Communication as group process mediator of aircrew performance. Aviation, Space, and Environmental Medicine. 1989 May.

50. Birch L, Jones N, Doyle PM, Green P, McLaughlin A, Champney C, Williams D, Gibbon K, Taylor K. Obstetric skills drills: evaluation of teaching methods. Nurse education today. 2007 Nov 1;27(8):915-22

51. *Cornthwaite K, Edwards S, Siassakos D. Reducing risk in maternity by optimising teamwork and leadership: an evidence-based approach to save mothers and babies. Best Practice \& Research Clinical Obstetrics \& Gynaecology. 2013 Aug 1;27(4):57181.

52. Sexton JB, Holzmueller CG, Pronovost PJ, Thomas EJ, McFerran S, Nunes J, Thompson DA, Knight AP, Penning DH, Fox HE. Variation in caregiver perceptions of teamwork climate in labor and delivery units. Journal of perinatology. 2006 Aug;26(8):463. 
53. *Siassakos D, Bristowe K, Draycott TJ, Angouri J, Hambly H, Winter C, Crofts JF, Hunt LP, Fox R. Clinical efficiency in a simulated emergency and relationship to team behaviours: a multisite cross-sectional study. BJOG: An International Journal of Obstetrics \& Gynaecology. 2011 Apr 1;118(5):596-607.

54. *Fransen AF, van de Ven J, Merién AE, de Wit-Zuurendonk LD, Houterman S, Mol BW, Oei SG. Effect of obstetric team training on team performance and medical technical skills: a randomised controlled trial. BJOG: An International Journal of Obstetrics \& Gynaecology. 2012 Oct 1;119(11):1387-93.

55. Beckett C.D., and Kipnis G.: Collaborative communication: integrating SBAR to improve quality/patient safety outcomes. J Healthc Qual 2009; 31: pp. 19-28

56. Guise JM, Segel SY, Larison K, Jump SM, Constable M, Li H, Osterweil P, Zimmer D. STORC safety initiative: a multicentre survey on preparedness \& confidence in obstetric emergencies. Qual Saf Health Care. 2010 Dec 1;19(6):e41-.

57. Mesinioti P, Angouri J, Draycott T, O'Brien S, Bristowe K, Siassakos D. 'Get me the airway there': negotiating leadership in obstetric emergencies. [Not Published]

58. Combs CA, Murphy EL, Laros JR. Factors associated with postpartum hemorrhage with vaginal birth. Obstetrics and gynecology. 1991 Jan;77(1):69-76.

59. Sosa CG, Althabe F, Belizán JM, Buekens P. Risk factors for postpartum hemorrhage in vaginal deliveries in a Latin-American population. Obstetrics and gynecology. 2009 Jun;113(6):1313.

60. Bais JM, Eskes M, Pel M, Bonsel GJ, Bleker OP. Postpartum haemorrhage in nulliparous women: incidence and risk factors in low and high risk women: a Dutch population-based cohort study on standard $(\geq 500 \mathrm{ml})$ and severe $(\geq 1000 \mathrm{ml})$ postpartum haemorrhage. European Journal of Obstetrics \& Gynecology and Reproductive Biology. 2004 Aug 10;115(2):166-72.

61. Sheiner E, Sarid L, Levy A, Seidman DS, Hallak M. Obstetric risk factors and outcome of pregnancies complicated with early postpartum hemorrhage: a 
population-based study. The Journal of Maternal-Fetal \& Neonatal Medicine. 2005 Jan 1;18(3):149-54.

62. Combs CA, Murphy EL, Laros JR. Factors associated with hemorrhage in cesarean deliveries. Obstetrics and gynecology. 1991 Jan;77(1):77-82. 